\title{
Incisional hernia recurrence after open elective repair: expertise in abdominal wall surgery matters
}

\author{
J. A. Pereira ${ }^{1,2^{*}}$ D, A. Bravo-Salva ${ }^{1}$, B. Montcusí ${ }^{1}$ S. Pérez-Farre ${ }^{1}$, L. Fresno de Prado ${ }^{2}$ and M. López-Cano 3,4
}

\begin{abstract}
Background: Recurrence after incisional hernia repair is one of the major problems related with this operation. Our objective is to analyze the influence of abdominal wall surgery expertise in the results of the open elective repair of incisional hernia.

Methods: We have compiled the data of a cohort of patients who received surgery for an incisional hernia from July 2012 to December 2015 in a University Hospital. Data were collected prospectively and registered in the Spanish Register of Incisional Hernia (EVEREG). The short- and long-term complications between the groups of patients operated on by the Abdominal Wall Surgery (AWS) unit and groups operated on by surgeons outside of the specialized abdominal wall group (GS) were compared.

Results: During the study period, a total of 237 patients were operated on by the open approach (114 AWS; 123 GS). One hundred seventy-five patients completed a median follow-up of 36.6 months [standard deviation (SD) $=6$ ]. Groups were comparable in terms of age, sex, body mass index (BMI), comorbidities, and complexity of hernia. Complications were similar in both groups. Patients in the AWS group presented fewer recurrences ( $12.0 \% \mathrm{vs}$. 28.9\%; $P=0.005)$. The cumulative incidence of recurrence was higher in the GS group [log rank 13.370; $P<0.001$; odds ratio $(\mathrm{OR})=37.8 ; 95 \%$ confidence interval $(\mathrm{Cl})=30.3-45.4]$. In the multivariate analysis, surgery performed by the AWS unit was related to fewer recurrences $(\mathrm{OR}=0.19 ; 95 \% \mathrm{Cl}=0.07-0.58 ; P<0.001)$.

Conclusion: Incisional hernia surgery is associated with better results in terms of recurrence when it is performed in a specialized abdominal wall unit.
\end{abstract}

Keywords: Incisional hernia, Open repair, Expertise, Recurrence, Abdominal wall unit

Incisional hernia repair is one of the most frequent procedures performed in General Surgery [1]. Although it is a common operation, real-world evidence shows high figures of incisional hernia recurrence (IHR) [2]. The Danish hernia registry reported a $12.7 \%$ IHR in 3212 patients [3]. A Swedish registry reported up to $23 \%$ IHR when the hernia width was greater than $3 \mathrm{~cm}$ and in onlay mesh repair [4] and, a Spanish registry reported $20.7 \%$ IHR after 1-year follow-up, especially in hernias

\footnotetext{
*Correspondence: jose.pereira@upf.edu

'Servicio de Cirugía General y del Aparato Digestivo, Parc de Salut Mar. Hospital del Mar. P, Marítim 23-25, 08003 Barcelona, Spain

${ }^{2}$ Departament de Ciències Experimentals i de la Salut, Universitat Pompeu

Fabra, Dr. Aiguader 80, 08003 Barcelona, Spain

Full list of author information is available at the end of the article
}

that were previously repaired (18.1\% primary vs. $30.6 \%$ recurrence) [5].

Risk factors for IHR have been related to patient characteristics (e.g., older age, obesity, diabetes, smoking, immunosuppression) [6], hernia characteristics (e.g., transverse diameter, location, recurrence, mesh) [6], and surgical performance (e.g., experience, dexterity, previous training) $[7,8]$.

Surgical expertise in abdominal wall surgery as a risk factor for IHR has been poorly studied [7, 8]. However, in other fields such as colorectal or bariatric surgery, a positive relationship of specialization and better results has been found [9-12]. Also, in heart surgery, expertise has been related to better outcomes [13].

(c) The Author(s). 2019 Open Access This article is distributed under the terms of the Creative Commons Attribution 4.0 International License (http://creativecommons.org/licenses/by/4.0/), which permits unrestricted use, distribution, and reproduction in any medium, provided you give appropriate credit to the original author(s) and the source, provide a link to the Creative Commons license, and indicate if changes were made. The Creative Commons Public Domain Dedication waiver (http://creativecommons.org/publicdomain/zero/1.0/) applies to the data made available in this article, unless otherwise stated. 
In the previous context, the aim of our study is to analyze the influence of surgeon specialization and expertise in abdominal wall surgery in incisional hernia outcomes, especially in recurrence.

\section{Patients and methods}

This is an observational cohort study of patients who received an open elective incisional hernia repair in a single center between July 2012 and December 2015. Data were compiled prospectively into the Spanish Incisional Hernia Registry (EVEREG) [14].

Patients were distributed in two groups: patients operated on by surgeons non-specialized in abdominal wall surgery (GS group), and patients who were operated on in the Abdominal Wall Surgery Unit (AWS group).

The AWS unit is comprised of a senior surgeon who specializes in abdominal wall surgery, a fellow, and a resident. In our General Surgery department 300 groin hernia, 150 primary or recurrent ventral hernia and 70 incisional hernia repairs are performed per year. The AWS unit performs approximately 150 inguinal hernia, 100 primary or recurrent ventral hernias and 50 incisional hernias elective repairs per year. All surgeries included in the AWS group were performed by the senior surgeon, or at least with the senior surgeon as first assistant. According to this parameters, our abdominal wall surgeon and center would achieve specialist required parameters published by different national organizations. [15-17] The rest of the surgeries performed were done by the GS group, conformed by 10 surgeons specialized in other fields. Due to the absence of criteria for the definition of specialization in abdominal wall surgery, we established some for this category, according to that suggested previously: high surgical volume and more than 5 years of surgical dedication to abdominal wall surgery [18].

All the risk factors related to abdominal wall complications were recorded [6]: age, sex, body mass index (BMI), surgical risk score from the American Society of Anesthesiologists (ASA), presence of chronic obstructive pulmonary disease (COPD), diabetes mellitus (DM), history of cancer, and immunosuppression.

Incisional hernias were classified according to location, width and length of hernia defect, and by complexity as defined by Slater [19] in three grades: severe, moderate, or minor.

The Carolinas Equation for Determining Associated Risks (CeDAR) score [20], which predicts complications and cost previous to surgery, was calculated for all patients.

Space mesh placement, type of mesh or fixation selection is chosen according to individual hernia cases and preference of each surgeon. AWS unit tendency during study period was to use anterior abdominal wall component separation and sub lay mesh position as primary option and composite meshes are only used when doubt of possible bowel contact is suspected. Despite hernia repair preferences each case is studied to give an individual tailored treatment. Variables related to technique (i.e., use of mesh, mesh position, type of mesh, associated procedures, and use of abdominal wall component separation) and variables related to the operation (i.e., time of surgery, intraoperative and postoperative complications, and length of stay) were also collected. Postoperative complications were stratified using the Clavien-Dindo system [21].

After hospital discharge, patients were followed up at 1 and 6 months, 1 year, and 2 years. In each visit, the presence of complications (e.g., chronic pain, chronic infection, presence of bowel fistula, and mesh removal) was assessed and recorded. Recurrence was evaluated on each follow-up visit by clinical exploration, and in case of doubt, an image exploration was indicated (ultrasound or computed tomography).

All patients and data analyzed in our study are registered and available for properly follow-up into Spanish Incisional Hernia Registry database, EVEREG [14]. We included all patients with at least one year follow-up for long-term outcomes and recurrence analysis. Time to hernia recurrence was calculated as the time from surgery to diagnosed recurrence.

Statistical analysis was performed using the SPSS v.20.0 (IBM Inc., Rochester, MN) statistical package. Quantitative variables are presented as the mean \pm standard deviation (SD), and categorical variables are presented as proportions. The association between qualitative variables was assessed using contingency tables (Chi-square test and Fisher test, when necessary) and the quantitative test using the Student $t$ test for unpaired data or the Mann-Whitney U test when necessary. The normality of the distribution of quantitative variables was checked using the Kolmogorov-Smirnov test. Statistical significance was established at $p<0.05$. The odds ratio (OR) of hernia recurrence was calculated for each group with its confidence intervals (CI).

Multivariate analysis of risk factors for incisional hernia was performed. Predictive capacity of each variable and its independence were analyzed using survival curves for Incisional hernia incidence was estimated by a non-parametric Kaplan-Meier method. A Cox proportional hazards regression model was used to select risk of $\mathrm{IH}$ recurrence.

The development of the study was performed following international guidelines of clinical investigation (Ethics Code and Helsinki Declaration) and according to legal regulations for confidentiality and personal data. The study protocol was approved by the local ethics committee. 


\section{Results}

A total of 237 patients received an open elective incisional hernia repair during the study period, with 114 patients in the AWS group and 123 in the GS group. No differences were found in preoperative characteristics between the groups, except a higher rate of previous cancer surgery in the GS group (GS 28.3\% vs. AWS 19\%; $P=0.01)$. In addition, the probability of surgical complications graded by the CeDAR equation score [20] was higher in patients in the AWS group (GS 15.33 vs. AWS 18.96; $P=0.02$ ) (Table 1).

Comparing hernia characteristics, we found no differences between groups in terms of location or grade of complexity. Moderate grade hernias were the most common in both groups, and there were more severe grade hernias in the AWS group without reaching statistical significance. Otherwise, hernias in the AWS group were larger (length > $10 \mathrm{~cm}$; GS $5.6 \%$ vs. AWS $27.2 \%$; $P=0.01$; width $>10 \mathrm{~cm}$; GS $13.8 \%$ vs. AWS 40.4\%; P = 0.01), and more patients in the AWS group had a previous repair (GS $15.4 \%$ vs. AWS 26.3\%; $P=0.02$ ) (Table 2).

Surgeries were performed mainly by senior surgeons in both groups (GS $61.8 \%$ vs. AWS 78.9\%; $P=0.09$ ). Comparison of repair techniques detected some differences. The most common technique in the GS group was suprafascial onlay mesh. The preferred type of mesh in the GS group was reticular polypropylene; whereas in the AWS group, it was composite. The sandwich technique ( 2 meshes in different layers) and abdominal components separation were used more frequently in AWS patients. Staples were the most frequent type of fixation in the GS group (56.8\%); whereas, suturing was the most frequent type of fixation in the AWS group (97.4\%)

Table 1 Preoperative Patient characteristics and comorbidities

\begin{tabular}{llll}
\hline & AWS N=114 & GS N=123 & P value \\
\hline Age, years (SD) & $63.8(12.5)$ & $66.2(10.9)$ & 0.45 \\
Age $>70 ~ N(\%)$ & $46(40.4)$ & $54(43.9)$ & 0.33 \\
Sex M/F N (\%) & $69(60.5) / 45(39.5)$ & $62(50.4) / 61(49.6)$ & 0.11 \\
BMI kg/m² (SD) & $29.1(4.7)$ & $29.0(4.3)$ & 0.55 \\
BMI > 25 N (\%) & $93(81.6)$ & $92(74.8)$ & 0.15 \\
BMI > 30 N (\%) & $46(40.4)$ & $50(40.7)$ & 0.53 \\
COPD N (\%) & $30(26.3)$ & $36(29.3)$ & 0.35 \\
DM N (\%) & $20(17.5)$ & $28(22.8)$ & 0.20 \\
Cancer N (\%) & $45(39.5)$ & $67(54.5)$ & $<0.001$ \\
Immunosuppression & $14(12.3)$ & $8(6.5)$ & 0.09 \\
N (\%) & & $41(33.3)$ & 0.08 \\
ASA class III/IV N (\%) & $49(43.0)$ & $15.33(9.9)$ & 0.02 \\
CeDAR Points (SD) & $18.96(14.0)$ &
\end{tabular}

AWS abdominal wall surgeon, GS general surgeon, COPD chronic obstructive pulmonary disease, $B M I$ body mass index, DM diabetes mellitus, ASA class American Society of Anesthesia Score, CeDAR Carolinas Equation for Determining Associated Risks score
Table 2 Incisional Hernia Characteristics

\begin{tabular}{llll}
\hline & AWS N=114 & GS N=123 & P value \\
\hline Location & & & \\
Midline N (\%) & $50(43.9)$ & $51(41.5)$ & 0.71 \\
Trocar Umbilical N (\%) & $29(25.4)$ & $38(30.9)$ & 0.35 \\
Parastomal N (\%) & $4(4.6)$ & $10(8.1)$ & 0.13 \\
Subcostal N (\%) & $5(4.4)$ & $6(4.9)$ & 0.86 \\
Lumbar N (\%) & $3(2.6)$ & $0(0)$ & 0.07 \\
Pfannenstiel N (\%) & $7(6.1)$ & $6(4.9)$ & 0.67 \\
Others N (\%) & $16(14.2)$ & $12(9.8)$ & 0.30 \\
Previous repair N (\%) & $30(26.3)$ & $19(15.4)$ & 0.02 \\
Complexity & & & 0.14 \\
Minor N (\%) & $22(19.3)$ & $34(27)$ & 0.31 \\
Moderate N (\%) & $65(57)$ & $69(56.1)$ & 0.13 \\
Severe N (\%) & $27(23.7)$ & $20(16.3)$ & $<0.001$ \\
Length > 10 cm N (\%) & $31(27.2)$ & $7(5.6)$ & $17(13.8)$ \\
Width > 10 cm N (\%) & $46(40.4)$ & & $<.001$ \\
\hline Slater N et a Her & & &
\end{tabular}

a Slater NJ et al. Hernia 2014; 18:7-17 [19]

Some meshes were fixated combining suture and staples into general surgery group (Table 3 ).

The length of surgery was longer into the AWS group, whereas in-hospital and postoperative complications and length of hospital stay were similar in both groups. Two patients in the AWS group died due to intestinal ischemia and acute heart failure, respectively (Table 4).

One-year follow-up was completed by 175 patients (median: $36.06 \mathrm{mo}$ ). The long- term complications showed no difference between groups. A higher percentage of recurrences was detected in the GS group compared with the AWS group (GS 28.9\% vs. AWS 12.0\%; $P=0.005$ ) (Table 4). This difference was also significative excluding parastomal hernias (GS $26.5 \%$ vs. AWS 9.2\%; $P=0.001)$.

The cumulative incidence of recurrences using a Cox survival analysis was higher in the GS group $(\mathrm{HR}=3.73$; 95\%; CI = 1.86-7.51) (Fig. 1).

Finally, using a multivariate analysis with a forward stepwise conditional logistic regression, only those surgeries performed by the AWS unit were related to less recurrence $(\mathrm{OR}=0.19 ; 95 \% ; \mathrm{CI}=0.07-0.58 ; \quad P<0.001$; Otherwise, three factors were strongly related to higher recurrence: midline $(\mathrm{OR}=5.81 ; 95 \% ; \mathrm{CI}=2.16-15.63$; $P=0.003)$ and parastomal location $(\mathrm{OR}=2.47 ; 95 \% ; \mathrm{CI}=$ 2.16-15.63; $\mathrm{P}<0.001)$ and previous hernia repair $(\mathrm{OR}=$ $3.21 ; 95 \% ; \mathrm{CI}=1.26-8.14 ; P=0.01$ ) (Table 5).

\section{Discussion}

Specialization in General and Digestive Surgery is common in some areas such as Colorectal Surgery, Hepatobiliary and Pancreatic Surgery, Gastrointestinal Surgery, 
Table 3 Characteristics of repair technique

\begin{tabular}{|c|c|c|c|}
\hline & $\begin{array}{l}\text { AWS } \\
N=114\end{array}$ & $\begin{array}{l}\text { GS } \\
N=123\end{array}$ & $P$ value \\
\hline \multicolumn{4}{|l|}{ Mesh position } \\
\hline Onlay N (\%) & $45(39.5)$ & $75(62)$ & $<0.001$ \\
\hline Sublay N (\%) & 66 (57.9) & 37 (30.6) & $<0.001$ \\
\hline Intraperitoneal N (\%) & $3(2.6)$ & $9(7.4)$ & $<0.001$ \\
\hline \multicolumn{4}{|l|}{ Type of mesh } \\
\hline Reticular N (\%) & $49(43)$ & $74(61.2)$ & $<0.001$ \\
\hline Laminar N (\%) & $1(0.9)$ & $2(1.7)$ & 0.52 \\
\hline Composite N (\%) & $63(55.3)$ & $46(38)$ & $<0.001$ \\
\hline \multicolumn{4}{|l|}{ Mesh fixation } \\
\hline Suture N (\%) & $111(97.4)$ & $63(52.1)$ & $<0.001$ \\
\hline Staples N (\%) & $17(14.9)$ & $68(56.2)$ & $<0.001$ \\
\hline Sandwich technique N (\%) ${ }^{a}$ & $34(29.8)$ & $7(5.8)$ & $<0.001$ \\
\hline $\begin{array}{l}\text { Anterior Components separation } \\
(\mathrm{ACS}) \mathrm{N}(\%)^{\mathrm{b}}\end{array}$ & $24(21)$ & $2(1.6)$ & $<0.001$ \\
\hline
\end{tabular}

a two mesh repair in different lays positioning

${ }^{\mathrm{b}}$ Anterior component separation as described by Ramirez with

mesh reinforcement

Obesity Surgery, Emergency Surgery, Surgical Oncology, Breast Surgery, and Endocrine Surgery, and this specialization is regulated and audited by boards using examinations and practice requirements [22]. In previous papers $[23,24]$, better outcomes have been demonstrated in high-level centers and by specialized surgeons. However, although some suggestions have been made $[15,16]$, until now abdominal wall surgery has had no specific regulation for specialization or to certify expertise.

Our study shows that surgeon specialization in abdominal wall surgery is one main factor to reduce recurrences in open elective incisional hernia repair. This fact also has been described in the Shouldice technique for inguinal hernia repair, performed at the Shouldice Hospital, which has a four-fold decreased risk of recurrence compared with mesh repair performed in generalist hospitals in Canada [25]. Low recurrence rates also have been related to specific techniques for ventral hernia repair, such as preperitoneal ventral hernia repair [26], achieving a $5.2 \%$ rate of recurrence; and, reoperation rates for recurrence, operative time, and costs were lower in high-volume surgeons ( $>36$ operations/year) [27].

No differences between groups of patients were observed, except a high percentage of patients with previous oncological surgery in the GS group. These patients received surgery for a previous oncologic condition from the same surgeon who performed the hernia repair. For this reason, also, there are more parastomal hernia repairs in GS group, patients were operated by the same surgeon that performed previous stoma surgery.

The complexity and type of hernia were similar in both groups. However, a higher percentage of patients in the AWS group had a previous hernia repair and higher transversal and longitudinal diameters. Both factors point to a higher probability of recurrences and complications in this group [28], whereas in our study, the results showed fewer recurrences during follow-up.

Table 4 Postoperative outcomes

\begin{tabular}{|c|c|c|c|}
\hline Short-term outcomes (30 postop days) & AWS $N=114$ & GS N $=123$ & $P$ value \\
\hline Length of stay days (SD) & $4.9(10.15)$ & $4.4(7.27)$ & 0.50 \\
\hline Operative time min (SD) & $103.8(73.21)$ & $83.3(52.58)$ & 0.01 \\
\hline Intraoperative complications N (\%) & $2(1.8)$ & $2(1.6)$ & 0.94 \\
\hline Postoperative short term complications N (\%) & $26(22.8)$ & $36(29.3)$ & 0.26 \\
\hline Exitus N (\%) & $2(1.8)$ & $0(0)$ & 0.14 \\
\hline Hematoma N (\%) & $2(1.8)$ & $6(4.9)$ & 0.18 \\
\hline Seroma N (\%) & $13(11.4)$ & $16(13)$ & 0.71 \\
\hline Wound infection N (\%) & $8(7)$ & $11(8.9)$ & 0.58 \\
\hline Skin necrosis N (\%) & $1(0.9)$ & $3(2.4)$ & 0.35 \\
\hline Urinary infection N (\%) & $2(1.8)$ & $4(3.3)$ & 0.46 \\
\hline Respiratory infection N (\%) & $2(1.8)$ & $4(3.3)$ & 0.46 \\
\hline Other complications N (\%) & $5(4.4)$ & $8(6.5)$ & 0.47 \\
\hline Reoperations N (\%) & $1(0.9)$ & $4(3.3)$ & 0.20 \\
\hline Follow-up outcomes (min. 1 year) & $N=92(80.7)^{a}$ & $N=83(67.7)^{a}$ & $P$ value \\
\hline Chronic infection N (\%) & 0 & $1(0.6)$ & 0.47 \\
\hline Mesh removal N (\%) & 0 & 0 & \\
\hline Recurrence N (\%) & $11(12)$ & $24(28.9)$ & 0.008 \\
\hline
\end{tabular}

a Percentage of completed follow-up from initial sample population 


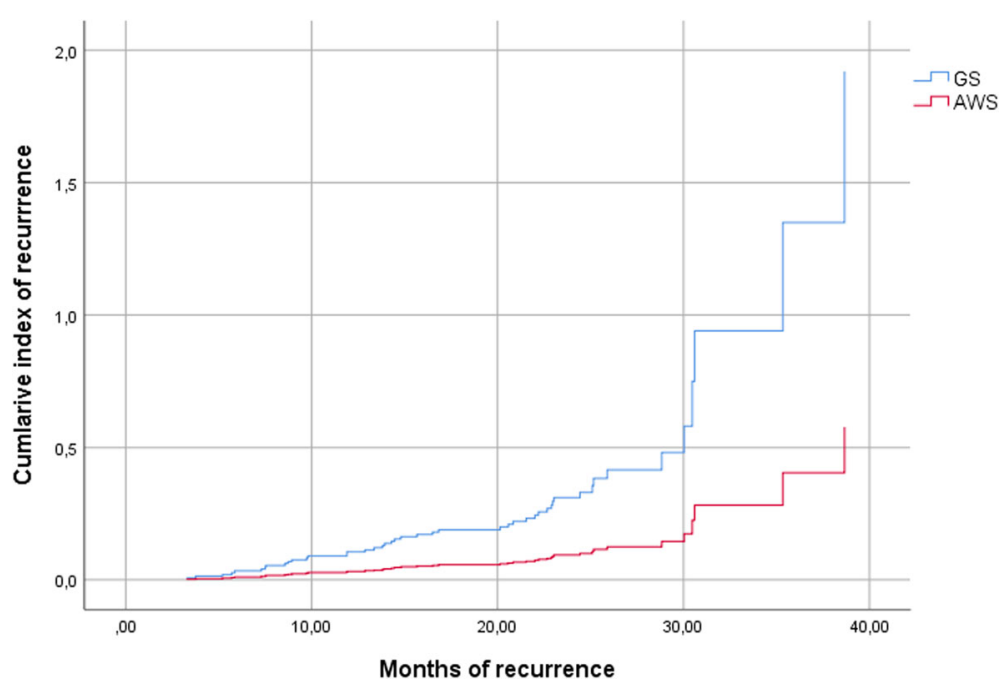

Fig. 1 Cumulative incidence of recurrence

The AWS group patients had a greater variability in the type of surgical techniques compared with the GS group. In our opinion, this fact could be related to a more tailored surgical approach and rational use of surgical resources in the AWS group. The GS surgeons more frequently used a reticular onlay mesh with staple fixation. These data are similar to those of our National Registry [5]. In our opinion, this suggests that more education in abdominal wall surgery should be provided in our country, and guidelines for the treatment of incisional hernias based on result of national and international registries should be developed. Further, membership on an international board for abdominal wall surgery should be mandatory for the leadership of specialized units.

The results of our study support the idea that elective incisional hernia repair should be performed by an Abdominal Wall Surgery Specialized Unit, and that the choice of the best surgical approach guided by expertise may be more important than the surgeon's surgical performance.

The strengths of our study are that all data were collected prospectively and registered so they can be checked and audited. The weaknesses are that, by the time of the study, our center had available only one specialized surgeon, and there is no clear consensus of

Table 5 Multivariate analysis of risk factors for recurrence

\begin{tabular}{llllll}
\hline & B & OR & Wald & $95 \% \mathrm{Cl}$ & $P$ value \\
\hline AWS unit & -1.61 & 0.20 & 8.75 & $0.07-0.58$ & 0.003 \\
Midline location & 1.76 & 5.81 & 12.14 & $2.16-15.63$ & $<0.001$ \\
Parastomal location & 2.47 & 11.86 & 4.67 & $1.26-111.82$ & 0.031 \\
Sutured mesh & -0.93 & 0.39 & 3.20 & $0.14-1.09$ & 0.073 \\
Previous repair & 1.35 & 3.85 & 6.95 & $1.14-10.50$ & 0.008 \\
\hline
\end{tabular}

abdominal wall surgeon or unit definition. On the other hand, our unit and specialized surgeon had both accomplished the requirements for certified hernia centers suggested in Italy and Germany $[15,16]$.

\section{Conclusions}

In conclusion, in this study, we found that any type of open elective incisional hernia repair performed by a specialized abdominal wall unit has a lower recurrence rate.

\section{Abbreviations}

ASA: American Society of Anesthesiologists; AWS: Abdominal wall surgeons; BMI: Body mass index; CeDAR: Carolinas Equation for Determining Associated Risks; COPD: Chronic obstructive pulmonary disease; DM: Diabetes mellitus;

GS: General surgeons; IHR: Incisional hernia recurrence

\section{Acknowledgements \\ Not applicable.}

\section{Authors' contributions}

$\mathrm{JP}$ and $\mathrm{ABS}$ were major contributors to writing the manuscript, and they contributed equally to this work, JP, BM and MLC were involved in the design of the study and drafting the manuscript, SPF and LFP collected and analysed data, MLC critically revised the manuscript till the final version was reached. All the authors read and approved the final manuscript.

\section{Funding}

No financial support was obtained for this study

\section{Availability of data and materials}

The datasets generated during and/or analysed during the current study are available from the corresponding author on reasonable request.

Ethics approval and consent to participate

Written informed consent was obtained from all individual participants included in the study. Data collection in EVEREG was approved by the Ethical Committee CEIC Parc de Salut Mar with number 2012/4908/I.

Consent for publication Not applicable. 


\section{Competing interests}

The authors declare that they have no competing interests.

\section{Author details}

'Servicio de Cirugía General y del Aparato Digestivo, Parc de Salut Mar. Hospital del Mar. P, Marítim 23-25, 08003 Barcelona, Spain. ${ }^{2}$ Departament de Ciències Experimentals i de la Salut, Universitat Pompeu Fabra, Dr. Aiguader 80, 08003 Barcelona, Spain. ${ }^{3}$ Servicio de Cirugía General y Digestiva, Hospital Vall d'Hebrón, Passeig Vall d'Hebrón 119-129, 08035 Barcelona, Spain. ${ }^{4}$ Departament de Cirurgia. Vall d'Hebrón, Universitat Autònoma de Barcelona, Passeig Vall d'Hebrón 119-129, 08035 Barcelona, Spain.

Received: 14 May 2019 Accepted: 29 July 2019

Published online: 07 August 2019

\section{References}

1. Poulose BK, Shelton J, Phillips S, et al. Epidemiology and cost of ventral hernia repair: making the case for hernia research. Hernia. 2012;16:179-83.

2. Helgstrand F, Rosenberg J, Kehlet H, Jorgensen LN, Bisgaard T. Nationwide prospective study of outcomes after elective incisional hernia repair. J Am Coll Surg. 2012;216:217-28.

3. Kokotovic D, Bisgaard T, Helgstrand F. Long-term recurrence and complications associated with elective incisional hernia repair. JAMA. 2016; 316:1575-82.

4. Israelsson LA, Smedberg S, Montgomery A, Nordin P, Spangen L. Incisional hernia repair in Sweden 2002. Hernia. 2006;10:258-61.

5. Pereira JA, López-Cano M, Hérnandez Granados P, Feliu X, et al. Initial results of the national registry of incisional hernia. Cir Esp May. 2016;94:595-602.

6. Liang MK, Holihan JL, Itani K, Alawadi ZM, Gonzalez JR, Askenasy EP, Ballecer C, Chong HS, Goldblatt MI, Greenberg JA, Harvin JA, Keith JN, Martindale RG, Orenstein S, Richmond B, Roth JS, Szotek P, Towfigh S, Tsuda S, Vaziri K, Berger DH. Ventral hernia management: expert consensus guided by systematic review. Ann Surg. 2017;265:80-9.

7. Aquina CT, Fleming FJ, Becerra A, Xu Z, Hensley BJ, Noyes K, Monson JRT, Jusko TA. Explaining variation in ventral and inguinal hernia repair outcomes: a population-based analysis. Surgery. 2017;162:628-39.

8. Ross SW, Oommen B, Kim M, Walters AL, Green JM, Heniford BT, Augenstein VA. Little slower, but just as good: postgraduate year resident versus attending outcomes in laparoscopic ventral hernia repair. Surg Endosc. 2014;28:3092-100.

9. García-Granero E, Navarro F, Cerdán Santacruz C, Frasson M, García-Granero A, Marinello F, Flor-Lorente B, Espí A. Individual surgeon is an independent risk factor for leak after double-stapled colorectal anastomosis: an institutional analysis of 800 patients. Surgery. 2017;162:1006-16.

10. Nikolian VC, Kamdar NS, Regenbogen SE, Morris AM, Byrn JC, Suwanabol PA, Campbell DA Jr, Hendren S. Anastomotic leak after colorectal resection: a population based study of risk factors and hospital variation. Surgery. 2017; 161:1619-27.

11. Shih T, Cole Al, Al-Attar PM, et al. Reliability of surgeon-specific reporting of complications after colectomy. Ann Surg. 2015;261:920-5.

12. Stroh C, Köckerling F, Lange V, Wolff S, Knoll C, Bruns C, Manger T, Obesity Surgery Working Group, Competence Network Obesity. Does certification as bariatric surgery center and volume influence the outcome in RYGB-data analysis of German bariatric surgery registry. Obes Surg. 2017:27:445-53.

13. Jha AK. Public reporting of surgical outcomes: surgeons, hospitals, or both. JAMA. 2017:318:1429-30

14. EVEREG. Registro Español de Hernia Incisional [Internet]. España: Servicio de Asesoría a la Investigación y Logística. http://www.evereg.es

15. Köckerling F, Berger D, Jost JO. What is a certified hernia center? The example of the German hernia society and German Society of General and Visceral Surgery. Front Surg. 2014;1(1):26.

16. Stabilini C, Cavallaro G, Bocchi P, Campanelli G, Carlucci M, Ceci F, Crovella F, Cuccurullo D, Fei L, Gianetta E, Gossetti F, Greco DP, lorio O, Ipponi P, Marioni A, Merola G, Negro P, Palombo D, Bracale U. Defining the characteristics of certified hernia centers in Italy: the Italian society of hernia and abdominal wall surgery workgroup consensus on systematic reviews of the best available evidences. Int J Surg. 2018;54(Pt A):222-35.

17. Köckerling F, Sheen AJ, Berrevoet F, et al. Accreditation and certification requirements for hernia centers and surgeons: the ACCESS project. Hernia. 2019;23:185-203.
18. Maruthappu M, Gilbert BJ, El-Harasis MA, Nagendran M, McCulloch P, Duclos A, Carty MJ. The influence of volume and surgical experience on individual surgical performance. Ann Surg. 2015;261:642-7.

19. Slater NJ, Montgomery A, Berrevoet F, Carbonell AM, Chang A, Franklin M, et al. Criteria for definition of a complex abdominal wall hernia. Hernia. 2014;18:7-17.

20. Augenstein A, Colavita PD, Wormer B, Walters AL, Bradley JF, Lincourt AE, Horton J, Heniford TB. CeDAR: Carolinas equation for determining associated risks. JACS. 2015;221:S65-6.

21. Dindo D, Demartines N, Clavien P-A. Classification of surgical complications: a new proposal with evaluation in a cohort of 6336 patients and results of a survey. Ann Surg. 2004;240:205-13.

22. European Union of medical specialists. Section of Surgery \& European Board of Surgery. https://uemssurg.org/divisions.

23. Birkmeyer JD, Stukel TA, Siewers AE, et al. Surgeon volume and operative mortality in the United States. N Engl J Med. 2003;349:2117-27.

24. Borowski DW, Kelly SB, Bradburn DM, Wilson RG, Gunn A, Ratcliffe AA, the members of the Northern Region Colorectal Cancer Audit Group. Impact of surgeon volume and specialization on short-term outcomes in colorectal cancer surgery. Br J Surg. 2007;94:880-9.

25. Malik A, Bell CM, Stukel TA, Urbach DR. Recurrence of inguinal hernia repair in a large hernia surgical speciality hospital and general hospitals in Ontario, Canada. Can J Surg. 2016;59:19-25.

26. Heniford BT, Ross SW, Wormer BA, Walters AL, Lincourt AE, Colavita PD, Kercher K, Augenstein VA. Preperitoneal ventral hernia repair: a decade long prospective observational study with analysis of 1023 patient outcomes: Ann Surg August 3 Volume Publish Ahead of Print - Issue p; 2018. https://doi.org/10.1097/SLA0000000000002966.

27. Aquina Ch T, Kelly KN, Probst CH, lannuzzi J, Noyes K, Langstein H, Monson $J$, Fleming F. Surgeon volume plays a significant role in outcomes and cost following open incisional hernia repair. J Gastrointest Surg. 2015;19:100-10.

28. Pereira JA, Montcusí B, López-Cano M, Hernández-Granados P, Fresno de Prado L. Members of the EVEREG registry. (2018) risk factors for bad outcomes in incisional hernia repair: lessons learned from the National Registry of incisional hernia (EVEREG). Cir Esp. 96:436-42.

\section{Publisher's Note}

Springer Nature remains neutral with regard to jurisdictional claims in published maps and institutional affiliations.

Ready to submit your research? Choose BMC and benefit from:

- fast, convenient online submission

- thorough peer review by experienced researchers in your field

- rapid publication on acceptance

- support for research data, including large and complex data types

- gold Open Access which fosters wider collaboration and increased citations

- maximum visibility for your research: over $100 \mathrm{M}$ website views per year

At $\mathrm{BMC}$, research is always in progress.

Learn more biomedcentral.com/submissions 